\title{
Exploring the effects of habit strength on scholarly publishing
}

\author{
Lars Moksness* \\ Svein Ottar Olsen
}

Ho Huy Tuu

\section{*Correspondence author}

Lars Moksness, University Library and School of Business and Economics, UiT The Arctic

University of Norway, N-9037 Tromsø, Norway, E-mail: lars.moksness@ outlook.com

Svein Ottar Olsen, School of Business and Economics, UiT The Arctic University of Norway,

N-9037 Troms $\varnothing$, Norway, E-mail: svein.o.olsen@uit.no

Ho Huy Tuu, Economics Faculty, Nha Trang University, 02, Nguyen Dinh Chieu, Nha Trang, Vietnam, E-mail: tuuhh@ntu.edu.vn 


\section{Introduction}

At present, there are two broad methods for research dissemination by scholarly articles, open access (OA) and non-open access (non-OA). While OA literature is freely available to consumers, non-OA literature is available only at a cost (e.g., for a journal subscription or single article download). The European Commission (2012) stated in the Europe 2020 strategy recommendation of 2012 that "publicly funded research should be widely disseminated through open access publication of scientific data and papers" (p. 2). Although the premise of OA seems reasonable and beneficial to the progress of science, adoption of this publishing model has been slow (Björk, 2017). Researchers are reluctant to fully embrace the model due to insecurities about the overall quality of OA material and an apparent lack of incentives that would reward the switch from nonOA to OA, although some suggestions are in the pipeline (European Commission, 2017).

Many actions performed on a daily basis are the results of habit (Wood and Rünger, 2016) and these automated behaviours have the advantage of reducing the cognitive load of decision-making (Ouellette and Wood, 1998). Scholarly publishing activities are influenced by familiarity with journals, scope, impact factors, editorial boards and requirements that facilitate researchers' decisions on where to submit their articles (Knight and Steinbach, 2008; Watkinson et al., 2016). Research has shown that familiarity and experience are important factors in habit formation (Lally et al., 2011) and also pertaining to scholarly publishing (Knight and Steinbach, 2008). One contemporary challenge surrounding scholarly publishing is to shift how we think about dissemination, accessibility and funding. Digitalization only shifted the medium of dissemination, while accessibility challenges how we think about the nature of dissemination itself. Habits, however, are firmly anchored in what we are used to, in this case traditional non-OA publishing. Overall, the publishing climate remains favourable towards maintaining the status quo irrespective of increasing demands by governments and funders to enable OA for research. However, it should be noted that there are interdisciplinary differences and some publishing cultures are more innovative and open towards, for instance, green OA than others (Fry, Spezl, Probets, and Creaser, 
2015). To our knowledge, no empirical studies have systematically investigated the role of habit strength (Verplanken and Orbell, 2003) in explaining or predicting scholarly OA/non-OA publishing intention and behaviour.

Several theories and antecedents compete to explain the process leading up to submitting an article to a journal (Aksulu and Wade, 2010; Dulle and Minishi-Majanja, 2011; Khalili and Singh, 2012; Moksness and Olsen, 2017; Park, 2009). Attitudes (Xia, 2010), trust (Watkinson et al., 2016), quality (Craft, 2016), normative influences (Hammarfelt and Rijcke, 2015; Migheli and Ramello, 2013) and incentives (van Dalen and Henkens, 2012) are among the frequently used explanations for publishing intention or behaviour. Even personality traits and identity are facets that in certain dimensions set researchers on different paths and underpin variations in decisionmaking (Busse and Mansfield, 1984; Feist, 1998). A line can be drawn between actions that are inherently elaborative and those that are automatic, of which attitudes and intentions are the former and habits are the latter (Ouellette and Wood, 1998; Wood and Neal, 2007). However, knowledge about how these factors influence or drive publishing intentions and behaviour in any larger sample of researchers is at best limited.

The theory of planned behaviour (TPB) is an influential framework for explaining a wide range of human activities and behaviours (Armitage and Conner, 2001; Fishbein and Ajzen, 2010), and habit is one of the constructs used to approach a deeper understanding of planned behaviour (De Bruijn, 2010; Verplanken et al., 1998). Prior works have investigated the multidimensionality of attitudes, norms and behavioural control, which subsequently lead to the expansion of the TPB (see Fishbein and Ajzen, 2010). The vast body of literature investigating the TPB ensures replicability of its basic structure, further enabling extensions to be tested with some measure of confidence (Armitage and Conner, 2001).

Thus, the aim of this study is to contribute to the emerging research stream that systematically investigates the deeper attitudinal and behavioural structure involved in OA and non-OA scholarly publishing (Dulle and Minishi-Majanja, 2011; Khalili and Singh, 2012; Moksness and Olsen, 
2017; Park, 2007). This article operates with broad definitions of OA and non-OA journals, and the TPB framework (Fishbein and Ajzen, 2010) is used to test alternative models within the context of OA intentions and behaviours. Subsequently, the traditional model will empirically test intention to submit to non-OA journals and non-OA publishing behaviours. We include an adapted habit automaticity subscale based on the Self-Reported Habit Index (SRHI; Gardner et al., 2011, 2012).

\section{Background and theoretical framework}

The veracity of the role of expectancy-value models in ascertaining publication intentions and behaviour is not well-documented, albeit with a few exceptions (Dulle and Minishi-Majanja, 2011; Khalili and Singh, 2012; Moksness and Olsen, 2017; Park, 2007, 2009). On the other hand, several studies have determined an array of considerations and influences that researchers contend with when selecting a publication outlet (Craft, 2016; Knight and Steinbach, 2008; Togia and Korobili, 2014; Xia, 2010). These determinants may be broadly grouped into attitudes towards the behaviour, the influence of norms, and the perceived ability to perform the behaviour.

The basic TPB framework describes behaviour as determined by its most proximal and central component, intention. Intentions are defined as the "motivational factors that influence a behavior; they are indicators of how hard people are willing to try, of how much of an effort they are planning to exert, in order to perform the behavior" (Ajzen, 1991, p. 181). The TPB is used to explain a wide range of intentions and behaviours (Armitage and Conner, 2001; Fishbein and Ajzen, 2010), but also extending into technology acceptance and usage (Pavlou and Fygenson, 2006) and open data or access adoption (Dulle and Minishi-Majanja, 2011; Harper and Kim, 2018; Kaba, 2018; Khalili and Singh, 2012; Moksness and Olsen, 2017). Typically, attitudes are found to have the strongest impact on intentions followed by norms and perceived behavioural control (PBC). According to Fishbein and Ajzen (2010), the attitudinal factor consists of an instrumental and an experiential component, which reflects a cognitive/affective split.

Social norms often refer to acceptable and permissible behaviour, actions or habits in families, groups or societies. Different academic disciplines emphasize different aspects with the norm 
construct. Thus norm has been conceptualized as "strict rules, as general guidelines, or simply as empirical regularities" (Fishbein and Ajzen, 2010: p. 129). For example, disciplinary norms are used to explain collective publishing behaviour, patterns or practices at the scholarly discipline level (Hammarfelt and Rijcke, 2015). This study defines norms within the reasoned action approach (TPB: Fishbein and Ajzen, 2010), as a perceived social expectations or pressure to submit their research articles to OA journals (injunctive norms) and how many researchers they know submit their research to OA journals (descriptive norms or behaviour of significant others) (Cialdini, Kallgren and Reno, 1991). In our study, norms are therefore conceptually and operationally separate from an individual researcher's cognitive habits (habit strength) or behavioural habits (how often or how much he or she publishes).

Finally, behavioural control reflects a distinction between ability and actual control to perform a behaviour. Some studies suggest that the intentional antecedents, such as norms (Cialdini, 2007), could benefit from being decomposed into their respective subscales depending on the research context, a notable example being the early work on the technology acceptance model (TAM) (Davis, 1986). Other approaches allowed for crossover effects between attitudes and norms resulting in development of the decomposed TPB (DTPB) (Taylor and Todd, 1995a, 1995b). Consequently, for the purposes of this study, the cognitive, descriptive and perceived ability components have been retained in an adaptation of the decomposed TPB.

What factors within the TPB framework are most important in explaining intention or publishing behaviour that differ between studies? Park (2009) found that attitudinal factors were the far most important, followed by perceived control in explaining web-based scholarly publishing. Factors related to social influence and perceived topical compatibility appeared to be insignificant. Those results were confirmed by Khalili and Singh (2012), suggesting that attitude and facilitating conditions, but not social influence, influenced acceptance of OA publishing. Dulle and Minishi-Majana (2011) concluded that attitudes and awareness explained behavioural intentions, but intention, facilitating conditions and social influence, among others, were found 
significantly to affect researcher's actual usage of OA. Moksness and Olsen (2017) concluded that attitudes were the strongest predictor of intention to publish OA, followed by injunctive and descriptive norms, and PBC capacity and autonomy. Finally, Massoro and Adewale (2019) found that subjective norms outperformed attitude in explaining intention to use OA journals. The very importance of disciplinary norms and external demands in explaining publishing behaviour has also been proposed by others (e.g., Hammarfelt and Rijcke, 2015; Migheli and Ramello, 2013).

Research on habit encompasses a wide array of topics and has a research stream spanning several decades in psychology (Yerkes and Dodson, 1908). Consequently, some different definitions of habit are found. For the purposes of this study, we rely on the definitions proposed by Triandis (1979), Verplanken and Aarts (1999) and Gardner (2015). For instance, Triandis (1979) viewed habit as automated behaviour not necessarily carried out with conscious awareness. The definition advanced by Gardner (2015) captured the nature of habit formation and activation (albeit originally intended as a definition of health-related habits), whereby "habit is a process by which a stimulus generates an impulse to act as a result of a learned stimulus-response association" (p. 1). In short, habit strength is the result of repeatedly performing a behaviour that reaches a point whereby an action is performed with a high degree of automaticity (Verplanken, 2006). Thus, this study views OA publishing habit strengths as initially being automated, non-effortful and goaldirected actions (Verplanken and Aarts, 1999).

Habit is an influential predictor of future behaviour (Wood and Rünger, 2016), a concept that arguably extends beyond the mere aggregation of the frequency of past behaviour (Verplanken and Orbell, 2003). Habit is found to directly affect behaviour, sometimes transcending the magnitude of the effects of the traditional TPB cognitions and intentions (Amoroso and Lim, 2017; Ouellette and Wood, 1998). Efforts have been undertaken to integrate habit strength in the TPB at various levels, including technology acceptance and usage (De Guinea and Markus, 2009). Habit is also suggested as a mechanism for maintaining lasting behavioural change (Gardner et al., 2015), a notion of particular interest in the present study. It is a relatively common practice to examine the 
interactive or additive effects of habit in TPB studies (Limayem et al., 2007; Verplanken and Aarts, 1999). However, the extant literature on OA adoption and behaviour (Dulle and Minishi-Majanja, 2011; Khalili and Singh, 2012; Park, 2007) does not contain any discussion or test of the role of habit strength in explaining or predicting academic publishing intention or behaviour. It is therefore pertinent to examine the possible effects of habit at various levels in our framework.

\section{Alternative roles of habit (strength)}

If and how habit is related to intention and behaviour within the TPB is not clear (Ajzen, 2002;

Gardner, 2015; Limayem et al., 2007; Ouellette and Wood, 1998). For example, habit is defined as an intentional antecedent in line with attitudes, norms and control (Honkanen et al., 2005), as a mediator between attitude and intention (Amoroso and Lim, 2017), and as a moderator between intention and behaviour (De Bruijn et al., 2007; Gardner et al., 2015; Limayem et al., 2007). The mediation model of habit between attitudes and intention has, however, received criticism due to theoretical and methodological shortcomings according to some researchers (Amoroso and Lim, 2017; Limayem et al., 2007). For example, Limayem et al. (2007) suggested that some of the studies supporting this approach suffered from not modelling habit according to its automaticity quality and relying on the frequency of behaviour instead. The authors also cited an omission of an actual behavioural measure, in addition to an uncertain theoretical argument for the model, as limitations of this approach. In order to assess whether proceeding with a mediation model is fruitful, the mediating qualities of habit strength (measured as automaticity) between the traditional intentional antecedents and intentions should therefore be tested. Based on the above review, different conceptual models are proposed in Figure 1 to visualize how the TPB dimensions (attitudes, norms and perceived behavioural control) relate to OA publishing habits among researchers and the effects of habit on intentions and behaviours (publish OA or non-OA). The development of the five various models is presented in Figure 1 and presented in the following sections. 
Figure 1. Alternative models

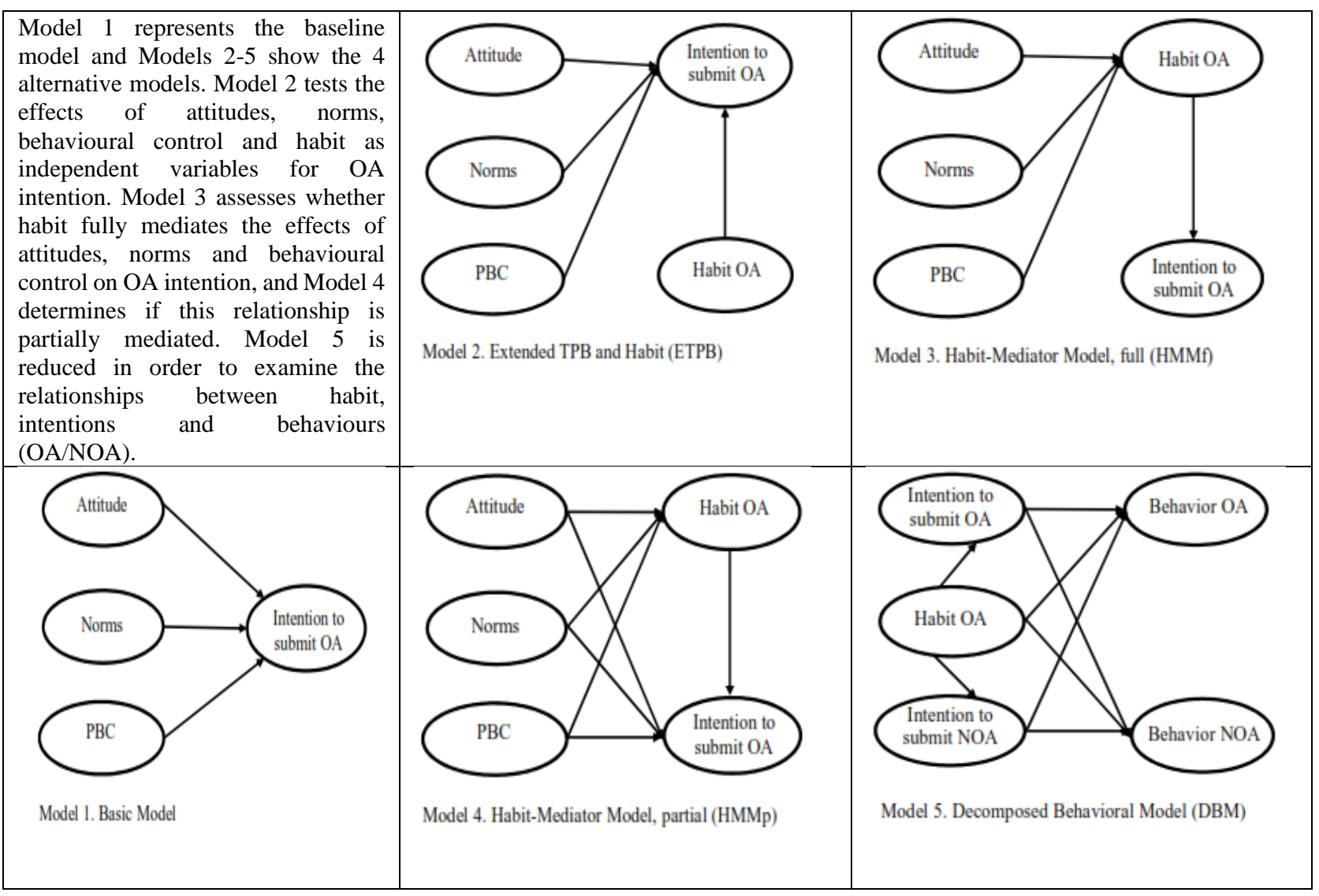

\section{Habit as an extension of the theory of planned behaviour}

The baseline model (Model 1) in this study is a decomposed and parsimonious version of the TPB in which the factorial relationships are expected to be replicated along the lines of previous studies utilizing similar frameworks (Dwivedi et al., 2017; Taylor and Todd, 1995b). Recall that attitudes are typically found as the foremost predictors of intention followed by norms and behavioural controls (Armitage and Conner, 2001; Fishbein and Ajzen, 2010). As such, researchers' attitudes towards submitting research articles to OA journals is expected to significantly and positively influence OA intentions over and above the effects of descriptive norms and PBC, respectively. However, in several of the TPB-related studies that examined a normative construct, the effect on intention has proven to be elusive, albeit a positive influence on behaviour is reported (Dulle and Minishi-Majanja, 2011; Khalili and Singh, 2012; Park, 2007). Khalili and Singh (2012) speculated that these results could be because publishing in OA journals had not obtained sufficient social 
influence. Given the influence of norms throughout academia (Linton et al., 2011; Migheli and Ramello, 2013), it is likely that the normative component will affect OA intentions as the field continues to mature (Harper and Kim, 2018; Kaba, 2018).

As presented in Model 2, habit strength in some studies is defined as an independent predictor of intention similar to attitudes, norms and behavioural controls (Honkanen et al., 2005). The notion of habit in this study rests on the premise that it is an automated and not elaborative behaviour even though it can be referred to as intentional (Verplanken and Orbell, 2003). This is an important distinction as both habitual intentions and intentions are goal directed per se; however, only one involves a conscious decision. Intentional behaviours do form the basis of habit development (Gardner, 2015), which also implies that habits should be able to influence future intentions and behaviour (Ouellette and Wood, 1998). For instance, Honkanen et al. (2005) suggested that the attitude-intention relationship is stronger among those who have well-developed intentions. If attitudes are weak, past behaviour may constitute the most salient piece of information and thus form the basis of evaluative intentions in a food context. Their results showed that past behaviour (frequency) is different from habit strength (automaticity), and past behaviour was found to influence intention over and above habit. Both constructs were superior determinants of intention as opposed to attitudes in their study.

Although the argument could support a direct effect by habit on intention (e.g., Amoroso and Lim, 2017), we suggest that certain specific research contexts, such as academic OA publishing, are governed by strong and deliberate attitudes, opinions and normative pressures that drive intention (Migheli and Ramello, 2013). Hence, in a model wherein the traditional intentional antecedents are present, any direct effect of habit will likely be mitigated. This means that when expressing conscious intentions to submit an article to an OA journal, it is expected that the salient and influential determinants on intention for researchers are their attitudes, the observed behaviour of peers, and the perceptions of their own capacity to perform the behaviour. That is, intention to submit to an OA journal encapsulates an elaborative and conscious effort or probability to engage 
in a behaviour and will be predicted by the intentional antecedents rendering the OA habit nonsignificant as a direct determinant.

\section{Habit-mediator models}

While the intentional determinants may trump the direct effects of habit on intention in this context, a question remains whether the effects of these variables can be mediated by habit within our research context. That is, does an automaticity specific habit strength subscale mediate the effects of attitudes, norms and behavioural capacity on intention to submit to OA journals? This question forms the basis for our two habit-mediator models (Models 3 and 4). Recall that this approach has received criticism in part due to the apparent lack of utilizing an automaticity specific habit construct (Limayem et al., 2007). Mediation translates to the effect on an outcome variable by one (or more) variables through one or more intervening or mediating variables (Baron and Kenny, 1986). Full mediation occurs when an antecedent variable only has an indirect effect on an outcome variable through an intervening or mediation variable, while partial mediation occurs when the direct effect of an antecedent variable is reduced but not rendered non-significant by the presence of a mediator (Baron and Kenny, 1986). The TPB provides a good example for both full and partial mediation (Fishbein and Ajzen, 2010), in which the effects of both attitudes and norms on behaviour are fully mediated by intention, whereas PBC is often modelled as being partially mediated by intention, which means it can have a direct effect on behaviour as well.

In order to explore this effect, we should first conduct an examination of the possible antecedents to ascertain whether they can generate habits. Instigating a task can be intentional; however, the continuation of a series of habitual actions as a result of the intentional act may themselves be unintentional (Verplanken and Aarts, 1999). Additionally, some researchers have considered any given habit as a behavioural script that acts as a mediator between situational cues and behaviour (Klöckner and Matthies, 2004). This viewpoint hails from the examination of the script concept by Abelson (1981), whereby scripts act as a knowledge structure and habit is a response programme. For instance, the act of preparing a manuscript to submit to a favourite 
journal consists of several behavioural steps, from the simplest (opening the browser) to the more complex (literature search) and so on. The habitual behaviour is, according to Klöckner and Matthies (2004), the result of these behavioural scripts and would constitute submitting the manuscript to a journal.

Habits are suggested to relate to constructs that are relatively stable over time. Several antecedents such as prior use (of an IT), perceived value, attitudes, satisfaction, importance and norms have previously been identified (Amoroso and Lim, 2017; Bayer et al., 2015; Hsiao et al., 2016; Limayem et al., 2007). Bayer et al. (2015) suggested that connection norms (in relation to an IT) have the potential to activate habits dependent on salience. Norms would appear to be the foremost contenders in relation to OA publishing (Migheli and Ramello, 2013), perhaps due to the observed behaviours of peers and the existence and influence of "invisible colleges" in academia (see Price, 1971). These normative structures possibly have more powerful direct effects on instigating automatic habitual behaviour than inquiring about researchers' conscious attitudes about whether adopted OA to one's own research is, for instance, good or bad. Thus, we may indeed find that habit is generated by the intentional antecedents we employed, in particular, norms. What is uncertain is the level of influence of each construct and whether habit channels these influences to an intention to submit an article to an OA journal.

Furthermore, if habit fully mediates the independent variables, we would find that they are no longer significant predictors of intention when habit is introduced into the model, and where the relationship is partially mediated we would observe a reduction in their respective effects on the mediator while still retaining a significant effect on intention (Baron and Kenny, 1986). For instance, Hsiao et al. (2016) investigated the mediation effects of habit and satisfaction on continuance usage intentions of mobile apps by perceived enjoyment and social ties. Although their results showed that the mediated effects were stronger through satisfaction, habit also proved to significantly mediate the effects of the independent variables. Similarly, Amoroso and Lim (2017) show that consumer attitudes are stronger predictors of continuance intention without 
mediation effects from habit, while consumer satisfaction only weakly predicts continuance intention and is mediated by habit.

\section{Decomposed dual behavioural model}

Our fifth model includes self-reported publishing behaviour (OA and non-OA). This model includes non-OA behaviour since university scholars have several outlets for publishing their articles. When a publishing habit has been formed, it likely influences both cognitions about where to submit articles (intention) and actual publishing behaviour. This relationship will also be determined by the individual researchers' level of habit strength, for instance, weak or emerging OA publishing habits may inconsistently influence the outcome (OA or non-OA publishing). Another possibility is that publishing behaviours undergo some process of routinization in order to become habitual (Gardner, 2015), and researchers are likely to be in different stages of the same habit-forming process at the same time. Routinization does not, however, necessarily equate to habituation (Ajzen, 2002), and routinized behaviour likely requires less cognitive effort to change.

Habit is a contributor of future intentions and behaviour (De Guinea and Markus, 2009; Ouellette and Wood, 1998). De Guinea and Markus (2009) suggested that an intended task can trigger habitual IT usage in that achieving the overarching task or goal necessitates the use of a computer, the Internet and text-editing software. Although the actions of using a computer are habitual, they need not be intentional to achieve the goal in this context. Situational or environmental cues may trigger habitual behaviours (Bargh and Ferguson, 2000). The behaviours may initially be intentional; however, the perpetuation of further behaviours can be unintentional (Verplanken and Aarts, 1999). Khalili and Singh (2012) recognized that possessing sufficient IT skills is necessary in order to successfully use OA, and Togia and Korobili (2014) cited unfamiliarity with the OA publishing model and how to find suitable OA journals to publish in as some of the major constraints in researchers' OA usage. Expanding on this line of reasoning, we see that submitting an article to a known journal is likely facilitated by some, if not most, of the steps in the process being habituated and thus performed automatically. 
Ouellette and Wood (1998) suggested that the frequency of previous behaviour is likely to have a favourable effect on future intentions, although the frequency of past behaviour is not necessarily an optimal proxy for habit (Limayem et al., 2007). The authors noted an important distinction, however, between behaviours that are performed daily or weekly and annually or biannually. Intentions were in this regard found to be the strongest predictors of future behaviour when the behaviour is performed infrequently. Intuitively this makes sense, when considering that the likely most salient feature of a behaviour that is performed frequently and in a stable context is the repeated performance of the behaviour itself. This is probably due to some form of recent effect (Murdock Jr., 1962), whereby the most accessible memory of a frequently performed behaviour is also the easiest to retrieve. However, this effect can also be due to weak attitudes (Honkanen et al., 2005). Publishing research articles is arguably an activity that takes place infrequently and thus should result in a more pronounced effect by intentions rather than habits on behaviour in our study.

A strategy to reduce confounding by the traditional independent variables is to deconstruct the model and assess the relative contribution of habit strength in a habit-intention-behaviour structure. Individuals can publish their work in either OA or non-OA or both and with different valences and levels of habit strength. In a study utilizing a similar framework as this article, Şimşekoğlu et al. (2015) found that car use habit strength reduces both public transport use intention and behaviour. The investigators discovered that individuals who have developed a habit for car use associated more barriers with using public transportation than their health-promoting counterparts who possessed no car use habit. Similar to OA adoption then, where the ideal outcome is arguably a public good, an established and disparate habit may indeed have negative consequences. Comparative strategies have previously been used in exploring or understanding the deeper structure of TPB or reasoned action frameworks (Dwivedi et al., 2017; Pavlou and Fygenson, 2006; Taylor and Todd, 1995a, 1995b). Although the decomposed TPB (Taylor and Todd, 1995b) 
in reality expands the number of factors that are typically assessed in a TPB model, our intention is to reduce the factors in order to isolate the effect of habit.

\section{Research methodology}

\section{Participants and procedures}

Data collection was conducted via email to 19,649 researchers from the major academic institutions in Norway in September 2017. Email addresses were collected from the institutional websites. Some websites did not differentiate between scientific and administrative personnel resulting in a significant ratio of recipients who did not fit the scope of the study. However, information about the surveyed institutions showed that the total number of scientific staff was 14,255 in 2016 (Regjeringen, 2017). The participants received an email invitation with a link to a web questionnaire. The requirement for participation was experience with scholarly publishing (have published or will publish scholarly articles). A total of 1,588 responses were received, which approximates an $11 \%$ response rate.

\section{Measurements}

Publishing behaviour was assessed by one item for each publishing paradigm, whereby the respondents indicated the frequency of their own publications in either OA or non-OA journals over the prior 2 -year period on a 10 -point scale where $1=0$ publications and $10=$ more than 10 published articles. We opted for a frequency measure to be able to differentiate the behavioural criterion from the automated habit subscale. Intention to submit to either an OA or a non-OA journal was measured on a 7-point scale ( $1=$ extremely unlikely to $7=$ extremely likely $)$ comprising 3 items reflecting whether the respondent is trying, intending or planning to submit articles to OA/non-OA journals (Fishbein and Ajzen, 2010; Khalili and Singh, 2012) (see Table 1).

Attitudes were measured on 7-point bipolar scales where the respondents first read the text "For me, submitting articles to OA journals is..." and then were asked to indicate if this is "useless - useful, bad-good, foolish - wise, " or "unimportant-important". These items have been found to reflect the cognitive or instrumental attitude component (Fishbein and Ajzen, 2010). Descriptive 
norms were measured by two items on a 7-point Likert-scale indicating the level of agreement with statements concerning the OA publishing frequency of their peers and to what extent they believed researchers they know publish in OA journals regularly. Perceived behavioural control (PBC) was measured on a 7-point scale by three items reflecting the level of control respondents felt they had in submitting research articles to OA journals. Both the descriptive norms and $P B C$ scales were constructed according to Fishbein and Ajzen (2010) and adapted to the research context.

The 5-item automaticity specific subscale of habit was based on the Self-Reported Behavioural Automaticity Index (SRBAI; Gardner et al., 2012), which was extracted from the 12-item SelfReport Habit Index (SRHI; Verplanken and Orbell, 2003) and was confirmed to perform well across studies (Gardner et al., 2012). The items were measured on a 7-point scale in the form: "The decision to submit an article to an OA journal is something.... (1) I do automatically, (2) I do without thinking, (3) I would find hard not to do, (4) That would require effort not to do it, and (5) I start doing before I realize I am doing it.

\section{Analytical procedures}

Structural equation modelling (SEM) is used in this study. SEM is a multivariate statistical analysis technique for analysing the structural relationship between measured variables and latent constructs based on the combination of factor analysis and multiple regression analysis (Kline, 2011). Compared to most other statistical methods, SEM has many advantages including the following capabilities: (1) treatment of both endogenous and exogenous variables as random variables with errors of measurement, (2) latent variables with multiple indicators and (3) modelling of mediating variables (Kaplan, 2000). Because SEM is a confirmatory rather than an exploratory method, it was chosen for the present study to test competing models. First, the intended constructs were assessed to ensure internal consistency and the convergent and discriminant validity (Anderson and Gerbing, 1988) by performing a confirmatory factor analysis. Second, the proposed models were tested using SEM applied for direct and indirect effects (Kline, 2011). Acceptable model fits are indicated by goodness of fit index (GFI) and comparative-fit 
index $(C F I)$ values exceeding 0.90 , and a root mean-square error of approximation (RMSEA) value below 0.08 (Browne and Cudek, 1992).

\section{Results}

\section{Reliability and validity of measures}

A confirmatory factor analysis (CFA) was conducted to ascertain construct reliability and validity. The analytical results showed the model fitted the data well $(G F I=0.97 ; C F I=0.99 ; R M S E A=$ 0.037). We also used a combination of methods for minimizing the impact of common method bias as suggested by Tehseen, Ramayah and Sajilan (2017). First, we used different formats of response (e.g., Likert type scale and bipolar scale) and a short introduction to the respondents before each construct measure in order to complete the measurements of the predictors and criteria variables. Second, we estimated a common method CFA model with the single common method factor added to the basic measurement model to detect the presence of common method bias (Podsakoff et al., 2003). The results showed that the fit of the common method CFA model was relatively worse $(G F I=0.95 ; C F I=0.98 ; R M S E A=0.051)$ than the basic measurement model $(G F I=0.97 ; C F I=$ 0.99; RMSEA = 0.037). Especially, the correlations were almost unchanged between the two models (see Table 2), showing that common method bias should not be a problem. 
Table 1. Standardized confirmatory factor analysis coefficients and construct reliabilities

\begin{tabular}{|c|c|c|c|c|}
\hline Constructs and indicators & $\begin{array}{l}\text { Factor } \\
\text { loadings }\end{array}$ & $\begin{array}{l}\text { t- } \\
\text { values }\end{array}$ & $\mathbf{C A}$ & VE \\
\hline 1. Attitudes OA: For me, submitting articles to OA journals is... & & & 0.93 & 0.75 \\
\hline Useless - useful & 0.89 & 44.4 & & \\
\hline Bad - good & 0.87 & 43.1 & & \\
\hline Foolish - wise & 0.86 & 42.3 & & \\
\hline Unimportant - important & 0.85 & 41.7 & & \\
\hline 2. Norms $O A$ & & & 0.89 & $\mathbf{0 . 8 0}$ \\
\hline Most researchers I know submit their research articles to OA journals regularly. & 0.87 & 41.2 & & \\
\hline $\begin{array}{l}\text { Of the researchers you know, how many submit their research articles to OA } \\
\text { journals regularly? }\end{array}$ & 0.91 & 43.9 & & \\
\hline 3.Perceived behavioural control $O A$ & & & 0.76 & $\mathbf{0 . 5 2}$ \\
\hline $\begin{array}{l}\text { How much personal control do you feel you have over submitting your research } \\
\text { articles to OA journals? }\end{array}$ & 0.60 & 23.4 & & \\
\hline $\begin{array}{l}\text { How confident are you that you will be able to submit your research articles to } \\
\text { OA journals? }\end{array}$ & 0.90 & 35.4 & & \\
\hline If I wanted to, I could easily submit my research articles to open access journals. & 0.63 & 25.0 & & \\
\hline $\begin{array}{l}\text { 4. Habit strength } \mathrm{OA} \text { : The decision to submit an article to an } O A \text { journal is } \\
\text { something... }\end{array}$ & & & $\mathbf{0 . 8 9}$ & 0.61 \\
\hline ...I do automatically. & 0.89 & 43.9 & & \\
\hline ...I do without thinking. & 0.86 & 41.8 & & \\
\hline ...I would find hard not to do. & 0.73 & 32.6 & & \\
\hline ...that would require effort not to do it. & 0.70 & 30.7 & & \\
\hline ...I start doing before I realize I am doing it. & 0.72 & 32.3 & & \\
\hline 5. Intention to submit to an OA journal & & & 0.98 & 0.94 \\
\hline I will try to submit research articles to OA journals within the next 2 years. & 0.96 & 51.1 & & \\
\hline I intend to submit research articles to OA journals within the next 2 years. & 0.99 & 54.7 & & \\
\hline I plan to submit research articles to OA journals within the next 2 years. & 0.95 & 51.6 & & \\
\hline 6. Intention to submit to a NOA journal & & & 0.97 & 0.91 \\
\hline I will try to submit research articles to NOA journals within the next 2 years. & 0.94 & 49.7 & & \\
\hline I intend to submit research articles to NOA journals within the next 2 years. & 0.98 & 54.1 & & \\
\hline $\begin{array}{l}\text { I plan to submit research articles to NOA journals within the next } 2 \text { years. } \\
\text { 7. Publishing behaviour } \boldsymbol{O A}\end{array}$ & 0.95 & 50.4 & & \\
\hline $\begin{array}{l}\text { How many articles would you say that you have published in OA journals within } \\
\text { the last } 2 \text { years? }\end{array}$ & 1.00 & 56.3 & - & - \\
\hline 8. Publishing behaviour NOA & & & & \\
\hline $\begin{array}{l}\text { How many articles would you say that you have published in NOA journals in the } \\
\text { last } 2 \text { years? }\end{array}$ & 1.00 & 56.3 & - & - \\
\hline
\end{tabular}

Notes. CA: Composite reliability; VE: Variance extracted.

As shown in Table 1, the reliability and validity of measures were confirmed by the values of composite reliability (>0.70) and variance extracted $(>0.50)$. The discriminant validity for the constructs is indicated by the square root of the AVE exceeding the correlations and are displayed in bold in Table 2 (Fornell and Larcker, 1981). The correlations were significant except for PBC and non-OA behaviour $(r=-0.03)$ (Table 2$)$. 
Table 2. Correlations and descriptive statistics for constructs in the measurement model

\begin{tabular}{|c|c|c|c|c|c|c|c|c|c|c|}
\hline $\mathrm{N}=1,588$ & Mean & SD & 1 & 2 & 3 & 4 & 5 & 6 & 7 & 8 \\
\hline \multicolumn{11}{|c|}{ The common method CFA model } \\
\hline 1. Attitude & 5.21 & 1.55 & & & & & & & & \\
\hline 2. Norms OA & 3.18 & 1.52 & 0.55 & & & & & & & \\
\hline 3. $\mathrm{PBC} \mathrm{OA}$ & 4.98 & 1.43 & 0.28 & 0.41 & & & & & & \\
\hline 4. Habit strength $\mathrm{OA}$ & 2.74 & 1.44 & 0.48 & 0.58 & 0.26 & & & & & \\
\hline 5. Intention to submit $\mathrm{OA}$ & 4.87 & 1.96 & 0.67 & 0.63 & 0.42 & 0.49 & & & & \\
\hline 6. Intention to submit NOA & 5.07 & 1.96 & -0.35 & -0.43 & -0.15 & -0.50 & -0.28 & & & \\
\hline 7. Behaviour OA & 3.10 & 2.69 & 0.20 & 0.36 & 0.23 & 0.19 & 0.33 & -0.06 & - & \\
\hline 8. Behaviour NOA & 4.28 & 3.19 & -0.28 & -0.24 & $-0.01^{n s}$ & -0.33 & -0.13 & 0.42 & 0.32 & - \\
\hline \multicolumn{11}{|c|}{ The basic measurement model } \\
\hline 1. Attitude & 5.21 & 1.55 & 0.87 & & & & & & & \\
\hline 2. Norms OA & 3.18 & 1.52 & 0.55 & 0.89 & & & & & & \\
\hline 3. $\mathrm{PBC} \mathrm{OA}$ & 4.98 & 1.43 & 0.28 & 0.41 & 0.72 & & & & & \\
\hline 4. Habit strength OA & 2.74 & 1.44 & 0.48 & 0.56 & 0.28 & 0.78 & & & & \\
\hline 5. Intention to submit OA & 4.87 & 1.96 & 0.67 & 0.63 & 0.42 & 0.48 & 0.97 & & & \\
\hline 6. Intention to submit NOA & 5.07 & 1.96 & -0.35 & -0.42 & -0.16 & -0.50 & -0.28 & 0.96 & & \\
\hline 7. Behaviour OA & 3.10 & 2.69 & 0.20 & 0.36 & 0.22 & 0.18 & 0.33 & -0.07 & - & \\
\hline 8. Behaviour NOA & 4.28 & 3.19 & -0.28 & -0.24 & $-0.03^{n s}$ & -0.34 & -0.13 & 0.42 & 0.32 & - \\
\hline
\end{tabular}

Notes. $n s=$ not significant; Remaining correlations are significant at $\mathrm{p}<0.001$; Intention to submit OA/NOA = Intention to submit open access/No open access; Bold numbers in the diagonal indicate the square root of the AVE.

\section{Structural analysis and model testing}

The results of structural equation analyses were shown in Table 3. First, an analysis was conducted on the intention to submit to an OA journal model (Model 1) with a good overall fit $(G F I=0.98$; $C F I=0.99 ; R M S E A=0.044)$. The explained variance of intention was $56.4 \%$. Second, when habit OA was included as an independent variable of intention (Model 2), the overall fit dropped slightly as opposed to Model $1(G F I=0.98 ; C F I=0.99 ; R M S E A=0.044)$. The impact of habit on intention was significant but with a weak magnitude $(\beta=0.05, p=0.031)$. The explained variance of intention was $56.6 \%$. 
Notes. $n s=$ not significant; Remaining correlations are significant at $\mathrm{p}<0.001$; Intention to submit OA/NOA = Intention to submit open access/No open access; Bold numbers in the diagonal indicate the square root of the AVE. 
Table 3. Model testing

\begin{tabular}{|c|c|c|c|c|c|c|c|c|c|c|c|}
\hline \multirow{3}{*}{ Paths } & \multirow{2}{*}{\multicolumn{2}{|c|}{$\begin{array}{c}\text { TPB } \\
\text { Model 1 } \\
\text { Basic Model }\end{array}$}} & \multicolumn{6}{|c|}{ TPB and Habit strength } & \multirow{2}{*}{\multicolumn{3}{|c|}{$\begin{array}{c}\begin{array}{c}\text { Decomposed } \\
\text { Behavioural Model }\end{array} \\
\text { Model 5 } \\
\text { (DBM) }\end{array}$}} \\
\hline & & & \multicolumn{2}{|c|}{$\begin{array}{c}\text { Model } 2 \\
\text { (ETBP) }\end{array}$} & \multicolumn{2}{|c|}{$\begin{array}{l}\text { Model 3 } \\
\text { (HMMf) }\end{array}$} & \multicolumn{2}{|c|}{$\begin{array}{c}\text { Model } 4 \\
\text { (HMMp) }\end{array}$} & & & \\
\hline & Std. $\beta$ & $P$-value & Std. $\beta$ & $\begin{array}{c}P- \\
\text { value }\end{array}$ & Std. $\beta$ & $\begin{array}{c}P- \\
\text { value }\end{array}$ & Std. $\beta$ & $\begin{array}{c}P- \\
\text { value }\end{array}$ & $\begin{array}{c}\text { Path } \\
\text { s }\end{array}$ & Std. $\beta$ & $P$-value \\
\hline A-I & 0.46 & $* *$ & 0,44 & 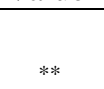 & - & 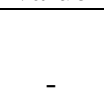 & 0,44 & 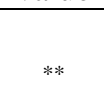 & $\begin{array}{l}\mathrm{H}-\mathrm{I}_{\mathrm{a}} \\
\mathrm{H}-\mathrm{I}_{\mathrm{b}}\end{array}$ & $\begin{array}{c}0.48 \\
-0.50\end{array}$ & $\begin{array}{l}* * \\
* *\end{array}$ \\
\hline $\begin{array}{l}\mathrm{A}-\mathrm{I}_{\mathrm{a}} \\
\mathrm{N}-\mathrm{I}_{\mathrm{a}}\end{array}$ & $\begin{array}{l}0.40 \\
0.30\end{array}$ & $* *$ & $\begin{array}{l}0.44 \\
0.28\end{array}$ & $* *$ & - & - & $\begin{array}{l}0.44 \\
0.28\end{array}$ & *** & $\begin{array}{l}n-1 b \\
H-B_{a}\end{array}$ & $\begin{array}{c}-0.50 \\
0.04\end{array}$ & 0.286 \\
\hline PBC-I $I_{a}$ & 0.16 & $* *$ & 0.16 & ** & - & - & 0.16 & $* *$ & $\mathrm{H}-\mathrm{B}_{\mathrm{b}}$ & -0.19 & $* *$ \\
\hline A-H & - & & - & - & 0.32 & ** & 0.26 & ** & $\mathrm{I}_{\mathrm{a}}-\mathrm{B}_{\mathrm{a}}$ & 0.34 & ** \\
\hline $\mathrm{N}-\mathrm{H}$ & - & & - & - & 0.43 & ** & 0.39 & ** & $\mathrm{I}_{\mathrm{a}}-\mathrm{B}_{\mathrm{b}}$ & 0.04 & 0.118 \\
\hline PBC-H & - & & - & - & 0.06 & 0.015 & 0.05 & 0.031 & $\mathrm{I}_{\mathrm{b}}-\mathrm{B}_{\mathrm{a}}$ & 0.06 & 0.033 \\
\hline $\mathrm{H}-\mathrm{I}_{\mathrm{a}}$ & - & & 0.05 & 0.031 & 0.59 & ** & 0.05 & 0.070 & $\mathrm{I}_{\mathrm{b}}-\mathrm{B}_{\mathrm{b}}$ & 0.34 & *** \\
\hline \multicolumn{12}{|l|}{ Model fit: } \\
\hline CMIN/df & \multicolumn{2}{|c|}{4.14} & \multicolumn{2}{|c|}{4.00} & \multicolumn{2}{|c|}{10.44} & \multicolumn{2}{|c|}{4.00} & \multicolumn{3}{|c|}{3.60} \\
\hline$G F I$ & \multicolumn{2}{|c|}{0.98} & \multicolumn{2}{|c|}{0.97} & \multicolumn{2}{|c|}{0.92} & \multicolumn{2}{|c|}{0.97} & \multicolumn{3}{|c|}{0.98} \\
\hline$C F I$ & \multicolumn{2}{|c|}{0.99} & \multicolumn{2}{|c|}{0.99} & \multicolumn{2}{|c|}{0.95} & \multicolumn{2}{|c|}{0.99} & \multicolumn{3}{|c|}{0.99} \\
\hline RMSEA & \multicolumn{2}{|c|}{0.044} & \multicolumn{2}{|c|}{0.044} & \multicolumn{2}{|c|}{0.077} & \multicolumn{2}{|c|}{0.044} & \multicolumn{3}{|c|}{0.040} \\
\hline $\mathrm{R}^{2} \mathrm{I}_{\mathrm{a}}$ & \multicolumn{2}{|c|}{0.564} & \multicolumn{2}{|c|}{0.566} & \multicolumn{2}{|c|}{0.347} & \multicolumn{2}{|c|}{0.566} & \multicolumn{3}{|c|}{0.232} \\
\hline $\mathrm{R}^{2} \mathrm{I}_{\mathrm{b}}$ & & - & & & & & & & & 0.253 & \\
\hline $\mathrm{R}^{2} \mathrm{~B}_{\mathrm{a}}$ & & - & & & & & & & & 0.123 & \\
\hline $\mathrm{R}^{2} \mathrm{~B}_{\mathrm{b}}$ & & - & & & & & & & & 0.205 & \\
\hline $\mathrm{R}^{2} \mathrm{H}$ & & - & & & & & & & & - & \\
\hline
\end{tabular}

Notes. $\mathrm{N}=1,588 ;{ }^{* *}=p<.001 ;$ Attitudes (A); Norms (N); Perceived behavioural control (PBC);

Habit $(\mathrm{H})$; Intention to submit OA $\left(\mathrm{I}_{\mathrm{a}}\right)$; Intention to submit NOA $\left(\mathrm{I}_{\mathrm{b}}\right)$; Behaviour OA $\left(\mathrm{B}_{\mathrm{a}}\right)$;

Behaviour NOA $\left(\mathrm{B}_{\mathrm{b}}\right)$.

In Model 3, we assessed whether habit as a full mediator between attitudes, norms and behavioural capacity would fit the data. The model fit is acceptable $(G F I=0.92 ; C F I=0.95$; $R M S E A=0.077)$. The explained variance in intention dropped from 56.6\% (Model 2) to $34.7 \%$, while attitude, norms and PBC explained $48.7 \%$ of the variance in habit. Model 4 assessing a partial mediation of habit showed an overall fit improved from that of Model $3(G F I=0.97 ; C F I=$ 0.99; RMSEA = 0.044). Compared with Model 3, the explained variance of intention increased from 34.7 to $56.6 \%$ while the explained variance of habit reduced from $48.7 \%$ to $36.2 \%$. However, the impact of habit on intention was non-significant $(\beta=0.05, p>0.05)$, suggesting that habit did not mediate the effect of attitudes, norms and perceived behavioural control on intention (Baron and Kenny, 1986). 
Model 5 explored the effects of habit on both OA and non-OA intentions and behaviours. This model fitted the data well $(G F I=0.98 ; C F I=0.99 ; R M S E A=0.040)$. Habit significantly influenced both OA $(\beta=0.48, p<0.001)$ and non-OA $(\beta=-0.50, p<0.001)$ intentions, which explained $25.3 \%$ and $23.2 \%$ of the variances of non-OA and OA intentions, respectively. A significantly negative effect of OA habit on non-OA behaviour was also found $(\beta=-0.19, p<$ 0.001), suggesting that OA habit reduced non-OA publishing behaviour. The variances explained of non-OA and OA behaviours were $20.5 \%$ and $12.3 \%$, respectively.

\section{Discussion and implications}

This study explored the role of habit strength and planned behaviour in relation to scholarly OA and non-OA publishing. Three main models were tested, which also included non-OA intentions and behaviour in the final model. The study used the TPB (Fishbein and Ajzen, 2010) and included habit strength measured by a Self-Reported Behavioural Automaticity Index (SRBAI; Gardner et al., 2012), a subscale of the SRHI (Verplanken and Orbell, 2003). The frameworks were adapted to the research context of academic publishing attitudes and behaviours.

This study contributes to the emerging research on publishing behaviour in several ways. First, we found that when measured alongside the traditional intentional antecedents, the effects of habit strength were rendered non-significant. A possibility is that the automaticity aspect of the decomposed habit subscale nullifies its direct effect on intentions in the presence of more rational attitudinal, normative and behavioural constructs. Especially if attitudes form the basis of intentions as well as the normative pressure (Honkanen et al., 2005; Migheli and Ramello, 2013), as is the case in the present study. Potential evidence for this was found in Models 3 and 4 wherein these constructs were tested as independent variables for habit mediating the effects on intentions. Habit was found to significantly affect intention only when it fully mediated the effects of the factors affecting intentions, albeit the model did not fit the data well. These results support the assumptions proposed by some prior studies (e.g., Amoroso and Lim, 2017; Limayem et al., 2007) 
which questioned the veracity of allowing habit to mediate any effects of the independent variables on intention.

However, an interesting discovery that emerged, especially from forcing a full mediation (Model 3), was the superior contribution of norms over attitudes in the prediction of habit strength. Descriptive norms guide behaviour by suggesting to individuals what is considered normal or typical behaviour, and our findings indicate that this is an integral part of developing OA publishing habits. According to Cialdini et al. (1991), norms do not necessarily need to be active at all times and in all contexts, as they vary in how noticable they are based on relevance and activation. This perspective fits with developing publishing habits, as the motivation to publish research papers likely is not salient with researchers at all times. Social and disciplinary norms are suggested to be important in forming intention and publishing behaviour include OA (Hammarfelt and Rijce, 2014; Massoro and Adewale, 2019; Migheli and Ramello, 2013; Moksness and Olsen, 2017). For instance, discussing the implementation of a new publishing policy is likely to trigger the activation of norms, leading to expressed intentions, possibly mediated by habit in some form. The analyses also showed that the researchers in this study significantly believed in their capacity to submit articles to OA journals; however, this belief only weakly contributes to habit strength. PBC directly affects intention in all models (i.e., Models 1-4).

Our fifth model, the decomposed behavioural model (DBM), represented the simplest attempt at exploring habitual publishing behaviour by decomposing the model to isolate the relative contribution of habit on the dependent variables. Intention and behaviour for non-OA publishing was also assessed. Decomposing the model and isolating the effects of habit was a fruitful strategy in our research context. However, this approach is in contrast to traditional decomposed TPB strategies (Dwivedi et al., 2017) wherein the belief structures of the independent variables are decomposed. It should further be noted that in Dwivedi et al. (2017), the fit indices indicated that DBM did not perform well. A key element of decomposition appears to be the increased focus the 
approach provides on the respective structures (Taylor and Todd, 1995b). In this sense, this present provides empirical evidence for this approach albeit in a simplified structure.

In our study, the results further revealed that when measured alone, habit strength does contribute to intentions, which is in line with other research (Amoroso and Lim, 2017; Honkanen et al., 2005; Ouellette and Wood, 1998). Habit strength OA was also found to reduce non-OA publishing behaviour, while the effect of OA behaviour was non-significant. The findings also confirmed the influence of OA intentions on behaviour, further suggesting that if habits are formed, this may indeed have a positive effect on publishing behaviour, albeit not directly. As expected, if researchers have developed a habit of publishing in OA journals, they appear to avoid non-OA journals, as evident by the non-significant effect of OA intentions on non-OA behaviour. A similar picture also emerges for non-OA intention, which only contributes to non-OA behaviour without being significantly associated with OA behaviour. OA habit strength, then, plays a part in forming intentions to publish in OA journals but reduces the intention to publish in non-OA journals. In contrast, the effects on behaviour are quite different. OA habit strength has no direct effect on OA publishing behaviour, which intuitively makes sense given that they are different psychological outcomes (one cannot elaborate on doing something automatically). However, evidence that habit plays a part in publishing can still be found in its negative influence on non-OA publishing behaviour, which also suggests it contributes to OA publishing.

According to Ouellette and Wood (1998), the manner in which habit directly contributes to future behaviours is determined by whether or not the domain in which the behaviour occurs is supportive of habits. They suggested that intentions mediate habits only when behaviour requires deliberate thought. This implies that a publishing habit is likely to influence behaviour directly if all of the subsequent actions leading up to the behaviour are habitual as well. Another point relates to whether the context remains stable over time (Gardner, 2015). Gardner (2015) noted that habit change interventions often fail given that people return to contexts whereby the implicit habit (automatic but performed infrequently) may be activated. 
There are some implications for researchers, administrators and policy makers. In the spring of 2018, the Research Council in Norway (NRC) signed the San Francisco Declaration on Research Assessment (DORA, 2012) (sfdora.org). This signals the NRC's desire, among other things, to evaluate research proposals based on the quality of the publications, not the journals in which they were published. However, the journal quality system, which also constitutes how funding is dispersed and thus incentivizes researchers to select high-level journals, is not being amended. This mismatch is likely to cause further discord among researchers and their institutions and funders, underscoring the importance of the present study. Few policy decisions that affect researchers appear to be founded on research, and in order to reduce friction in the upcoming transitional process, we not only need more research, but the research has to be implemented practically.

In a national sample of researchers, OA publishing habits were found to predict intentions to submit to OA journals and reduce publishing behaviour in non-OA journals. The challenge herein is to allow habits the time to form given that producing scholarly articles is an infrequent behaviour. While researchers' intentions do predict behaviour, our findings suggest that this holds true for both OA and non-OA behaviour, albeit comparatively more weakly for non-OA behaviour. Still, when the national (e.g., Norway) goal is to have all research openly available by 2024 , it is worth considering that OA habit strength is the only predictor, in this study, that causes a reduction in the "undesired" behaviour. Also worth noting is that when it comes to OA publishing, researchers' attitudes and normative influences are potent and override any direct effect habit may have on intentions. However, when isolating habit from these predictors, habit explains a significant portion of the intentions. This shows that when working with researchers in relation to OA publishing, it is primarily their attitudes and norms that will dictate their intentions.

It is worth considering that descriptive publishing norms, as measured in our study, may be pivotal components in facilitating the transition to open science by their direct path to habit strength. A typical approach to educate researchers about $\mathrm{OA}$ is by giving presentations and lectures, although this is usually done in single presentations and not at regular intervals. If a 
publishing habit that is connected to non-OA already exists, it is likely to remain dominant or at least reactivate when researchers return to their typical working context. A possible solution that may facilitate the development of an OA publishing habit could therefore be to schedule workshops or seminars at regular intervals. Indeed, in reviewing the habit literature, Wood and Rünger (2016) found that habit formation is more likely to occur when the desired behaviour is repeated and there are interval reward schedules in place.

\section{Limitations and future research}

This paper contributes not only to the understanding of open access scholarly publishing, but is also relevant for research on what drives (academic) data sharing (e.g., Fecher et al., 2015; Zuiderwijk and Spiers, 2019), knowledge sharing, the sharing economy or the open source movement (Aksulu and Wade, 2010; Attard et al., 2015). Including other individual forces (e.g., personality and personal values) and the role of habit strength into these research areas should be considered. The present study tested several models but did not assess actual behaviour within a setting that allows for improved control over causality. The respondents took the survey at various times over several weeks, which means there were possible confounding factors in their environment that could not be controlled for.

Future research should strive to develop intervention approaches (e.g., money or norms incentives) in cooperation with governments, policy makers and funding bodies to maximize effectiveness. Ideally, a study of this kind would benefit from being conducted in concert with the development and implementation of new policies and guidelines (Attard et al., 2015). We briefly discussed how possessing sufficient IT skills is likely to facilitate publishing both OA and non-OA. The current study found that norms are the most influential contributors to habit strength, and the role of norms in academic life and publishing practices is well-documented (Linton et al., 2011; Migheli and Ramello, 2013). However, a systematic investigation of how norms (Cialdini et al., 1990) influence publishing habits is notably absent.

\section{References}


Abelson, R.P. (1981), "Psychological status of the script concept", American Psychologist, Vol. 36 No, 7, pp. 715-729.

Ajzen, I. (1991), “The theory of planned behaviour", Organizational Behavior and Human Decision Processes, Vol. 50 No. 2, pp. 179-211.

Ajzen, I. (2002), "Residual effects of past on later behavior: Habituation and reasoned action perspectives”, Personality and Social Psychology Review, Vol. 6 No. 2, pp. 107-122.

Aksulu, A. and Wade, M. (2010), “A comprehensive review and synthesis of open source research", Journal of the Association for Information Systems, Vol. 11 No. 11, pp. 576-656.

Amoroso, D. and Lim, R. (2017), “The mediating effects of habit on continuance intention”, International Journal of Information Management, Vol. 37, pp. 693-702.

Anderson, J.C. and Gerbing, D.W. (1988), "Structural equation modelling in practice: A review and recommended two-step approach", Psychological Bulletin, Vol. 103 No. 3, pp. 411423.

Armitage, C.J. and Conner, M. (2001), "Efficacy of the theory of planned behaviour: A metaanalytic review", British Journal of Social Psychology, Vol. 40 No. 4, pp. 471-499.

Attard, J., Orlandi, F., Scerri, S. and Auer, S. (2015), “A systematic review of open government data initiatives", Government Information Quarterly, Vol. 32, pp. 399-418.

Bargh, J.A. and Ferguson, M.J. (2000), "Beyond behaviorism: On the automaticity of higher mental processes", Psychological Bulletin, Vol. 126 No. 6, pp. 925-945.

Baron, R.M. and Kenny, D.A. (1986), “The moderator-mediator variable distinction in social psychological research: Conceptual, strategic, and statistical considerations", Journal of Personality and Social Psychology, Vol. 51 No. 6, pp. 1173-1182.

Bayer, J.B., Campbell, S.W. and Ling, R. (2015), "Connection cues: Activating the norms and habits of social connectedness", Communication Theory, Vol. 26 No. 2, pp. 128-149.

Björk, B.-C. (2017), “Open access to scientific articles: A review of benefits and challenges”, Internal and Emergency Medicine, Vol. 12 No. 2, pp. 247-253. 
Browne, M.W. and Cudeck, R. (1992), “Alternative ways of assessing model fit”, Sociological Methods and Research, Vol. 21 No. 2, pp. 230-258.

Busse, T.V. and Mansfield, R.S. (1984), "Selected personality traits and achievement in male scientists", The Journal of Psychology, Vol. 116 No. 1, pp. 117-131.

Cialdini, R.B. (2007), "Descriptive social norms as underappreciated sources of social control”, Psychometrika, Vol. 72 No. 2, pp. 263-268.

Cialdini, R.B., Kallgren, C.A. and Reno, R.R. (1991), “A focus theory of normative conduct: A theoretical refinement and reevaluation of the role of norms in human behavior", Advances in Experimental Social Psychology, Vol. 24, pp. 201-234.

Cialdini, R.B., Reno, R.R. and Kallgren, C.A. (1990), “A focus theory of normative conduct: recycling the concept of norms to reduce littering in public places", Journal of Personality and Social Psychology, Vol. 58 No. 6, pp. 1015-1026.

Craft, A.R. (2016), “Is this a quality journal to publish in? How can you tell?”, Serials Review, Vol. 42 No. 3, pp. 237-239.

Davis, F.D. (1986), A Technology Acceptance Model for Empirically Testing New End-User Information Systems: Theory and Results, $\mathrm{PhD}$ dissertation, Massachusetts Institute of Technology.

De Bruijn, G.-J. (2010), “Understanding college students' fruit consumption. Integrating habit strength in the theory of planned behaviour", Appetite, Vol. 54 No. 1, pp. 16-22.

De Bruijn, G.-J., Kremers, S. P., De Vet, E., De Nooijer, J., Van Mechelen, W. and Brug, J. (2007), "Does habit strength moderate the intention-behaviour relationship in the Theory of Planned Behaviour? The case of fruit consumption", Psychology and Health, Vol. 22 No. 8, pp. 899-916.

De Guinea, A.O. and Markus, M.L. (2009), "Why break the habit of a lifetime? Rethinking the roles of intention, habit, and emotion in continuing information technology use", $M I S$ Quarterly, Vol. 33 No. 3, pp. 433-444. 
The Declaration on Research Assessment (DORA) (2012), In the Annual Meeting of the American Society for Cell Biology in San Francisco. https://sfdora.org/read/

Dulle, F.W. and Minishi-Majanja, M. (2011), "The suitability of the unified theory of acceptance and use of technology (UTAUT) model in open access adoption studies”, Information Development, Vol. 27. No. 1, pp. 32-45.

Dwivedi, Y.K., Rana, N.P., Janssen, M., Lal, B., Williams, M.D. and Clement, M. (2017), “An empirical validation of a unified model of electronic government adoption (UMEGA)", Government Information Quarterly, Vol. 34 No. 2, pp. 211-230.

European Commission (2012), Commission Recommendation on Access to and Preservation of Scientific Information, Brussels. Retrieved from http://ec.europa.eu/research/sciencesociety/document_library/pdf_06/recommendation-access-and-preservation-scientificinformation_en.pdf.

European Commission (2017), Evaluation of Research Careers fully Acknowledging Open Science Practices; Rewards, Incentives and/or Recognition for Researchers Practicing Open Science, Luxemburg: Publications Office of the European Union.

Fecher, G., Friesike, S. and Hebing, M. (2015), "What drives academic data sharing? PLOS ONE, DOI:10.1371/journal.pone.0118053.

Feist, G.J. (1998), “A meta-analysis of personality in scientific and artistic creativity”, Personality and Social Psychology Review, Vol. 2 No. 4, pp. 290-309.

Fishbein, M. and Ajzen, I. (2010), Predicting and Changing Behavior: The Reasoned Action Approach. New York: Taylor and Francis.

Fornell, C. and Larcker, D.F. (1981), "Structural equation models with unobservable variables and measurement error: Algebra and statistics”, Journal of Marketing Research, Vol. 18 No. 3, pp. 382-388.

Fry, J., Spezi, V., Probets, S., \& Creaser, C. (2015). Towards an understanding of the relationship between disciplinary research cultures and open access repository behaviors. Journal of 
the Association for Information Science and Technology, 67(11), 2710-2724.

doi:10.1002/asi.23621

Gardner, B. (2015), “A review and analysis of the use of 'habit' in understanding, predicting and influencing health-related behaviour", Health Psychology Review, Vol. 9 No. 3, pp. $277-$ 295.

Gardner, B., Abraham, C., Lally, P. and de Bruijn, G.-J. (2012), “Towards parsimony in habit measurement: Testing the convergent and predictive validity of an automaticity subscale of the Self-Report Habit Index", International Journal of Behavioral Nutrition and Physical Activity, Vol. 9 No. 1, pp. 1-12.

Gardner, B., Corbridge, S. and McGowan, L. (2015), “Do habits always override intentions? Pitting unhealthy snacking habits against snack-avoidance intentions”, BMC Psychology, Vol. 3 No1, pp. 1-9.

Gardner, B., de Bruijn, G.-J. and Lally, P. (2011), “A systematic review and meta-analysis of applications of the self-report habit index to nutrition and physical activity behaviours", Annals of Behavioral Medicine, Vol. 42 No, 2, pp. 174-187.

Hammarfelt, B. and de Rijeke, S. (2015), “Accountability in context: effects of research evaluation systems on publication practices, disciplinary norms, and individual working routines in the faculty of Arts at Uppsala University”, Research Evaluation, Vol. 24, pp. 63-77.

Harper, L.M. and Kim, Y. (2018), “Attitudinal, normative, and resource factors affecting psychologists' intentions to adopt an open data badge: An empirical analysis”, International Journal of Information Management, Vol. 41, pp. 23-32.

Honkanen, P., Olsen, S.O. and Verplanken, B. (2005), "Intention to consume seafood-the importance of habit”, Appetite, Vol. 45 No. 2, pp. 161-168.

Hsiao, C.-H., Chang, J.-J. and Tang, K.-Y. (2016), "Exploring the influential factors in continuance usage of mobile social Apps: Satisfaction, habit, and customer value perspectives", Telematics and Informatics, Vol. 33 No. 2, pp. 342-355. 
Kaba, B. (2018), "Modeling information and communication technology use continuance behavior: Are there differences between users on basis of their status?" International Journal of Information Management, Vol. 38, pp. 77-85.

Kaplan, D. (2000), Structural Equation Modeling: Foundations and Extensions, Sage Publications, Newbury Park, CA.

Khalili, L. and Singh, D. (2012), "Factors influencing acceptance of open access publishing among medical researchers in Iran”, Libri, Vol. 62 No. 4, pp. 336-354.

Kline, R.B. (2011), Principles and Practice of Structural Equation Modeling, New York, N.Y.: Guilford Press.

Klöckner, C.A. and Matthies, E. (2004), "How habits interfere with norm-directed behaviour: A normative decision-making model for travel mode choice", Journal of Environmental Psychology, Vol. 24 No. 3, pp. 319-327.

Knight, L.V. and Steinbach, T.A. (2008), "Selecting an appropriate publication outlet: A comprehensive model of journal selection criteria for researchers in a broad range of academic disciplines”, International Journal of Doctoral Studies, Vol. 3, pp. 59-79.

Lally, P., Wardle, J. and Gardner, B. (2011), "Experiences of habit formation: A qualitative study", Psychology, Health and Medicine, Vol. 16 No. 4, pp. 484-489.

Limayem, M., Hirt, S.G. and Cheung, C.M. (2007), "How habit limits the predictive power of intention: The case of information systems continuance", MIS Quarterly, Vol. 31 No. 4, pp. $705-737$.

Linton, J.D., Tierney, R. and Walsh, S.T. (2011), "Publish or perish: How are research and reputation related?" Serials Review, Vol. 37 No. 4, pp. 244-257.

Massoro, Z.Z. and Adewale, N.T. (2019), "Influence of attitude, subjective norms and personal innovativeness on intention to use open access journals: a case of agricultural research institute”, Library Philosophy and Practice (e-journal), http://digitalcommons.unl.edu/libphilprac/2484. 
Migheli, M. and Ramello, G.B. (2013), “Open access, social norms and publication choice”, European Journal of Law and Economics, Vol. 35 No. 2, pp. 149-167.

Moksness, L. and Olsen, S.O. (2017), “Understanding researchers' intention to publish in open access journals", Journal of Documentation, Vol. 73 No. 6, pp. 1149-1166.

Murdock Jr, B.B. (1962), “The serial position effect of free recall”, Journal of Experimental Psychology, Vol. 64 No. 5, pp. 482-488.

Ouellette, J.A. and Wood, W. (1998), "Habit and intention in everyday life: the multiple processes by which past behavior predicts future behaviour", Psychological Bulletin, Vol. 124 No. 1, pp. 54-74.

Park, J.-H. (2007), Factors Influencing the Adoption of Open Access Publishing, PhD dissertation, Syracuse University.

Park, J.-H. (2009), “Motivations for web-based scholarly publishing: Do scientists recognize open availability as an advantage?” Journal of Scholarly Publishing, Vol. 40 No. 4, pp. 343-369.

Pavlou, P.A. and Fygenson, M. (2006), "Understanding and predicting electronic commerce adoption: An extension of the theory of planned behaviour", MIS Quarterly, Vol. 30 No. 1, pp. 115-143.

Podsakoff, P.., MacKenzie, S. B., Lee, J. Y. and Podsakoff, N. P. (2003), “Common method biases in behavioral research: A critical review of the literature and recommended remedies", Journal of Applied Psychology, Vol. 88 No. 5, pp. 879-903.

Regjeringen (Norwegian guvernement) $(2017,15.11 .2017)$, “Statistics for universities and colleges 2016 / Nøkkeltall for statlige universiteter og høyskoler 2016. Retrieved from http://dbh.nsd.uib.no/dbhvev/esdata/2016/nokkeltall_statlige_2016.pdf

Şimşekoğlu, Ö., Nordfjærn, T. and Rundmo, T. (2015), “The role of attitudes, transport priorities, and car use habit for travel mode use and intentions to use public transportation in an urban Norwegian public", Transport Policy, Vol. 42, pp. 113-120. 
Taylor, S. and Todd, P.A. (1995a), "Decomposition and crossover effects in the theory of planned behavior: A study of consumer adoption intentions", International Journal of Research in Marketing, Vol. 12 No. 2, pp. 137-155.

Taylor, S. and Todd, P.A. (1995b), “Understanding information technology usage: A test of competing models", Information Systems Research, Vol. 6 No. 2, pp. 144-176.

Tehseen, S., Ramayah, T. and Sajilan, S. (2017), “Testing and controlling for common method variance: A review of available methods", Journal of Management Sciences, Vol. 4 No. 2, pp. 142-168.

Togia, A. and Korobili, S. (2014), “Attitudes towards open access: A meta-synthesis of the empirical literature", Information Services and Use, Vol. 34 No. 3-4, pp. 221-231.

Triandis, H.C. (1979), "Values, attitudes, and interpersonal behaviour”, Paper presented at the Nebraska Symposium on Motivation.

van Dalen, H.P. and Henkens, K. (2012), "Intended and unintended consequences of a publish-orperish culture: A worldwide survey", Journal of the American Society for Information Science and Technology, Vol. 63 No. 7, pp. 1282-1293.

Verplanken, B. (2006), "Beyond frequency: Habit as mental construct”, British Journal of Social Psychology, Vol. 45 No. 3, pp. 639-656.

Verplanken, B. and Aarts, H. (1999), "Habit, attitude, and planned behaviour: Is habit an empty construct or an interesting case of goal-directed automaticity?" European Review of Social Psychology, Vol. 10 No. 1, pp. 101-134.

Verplanken, B., Aarts, H., Knippenberg, A. and Moonen, A. (1998), “Habit versus planned behaviour: A field experiment”, British Journal of Social Psychology, Vol. 37 No. 1, pp. 111-128.

Verplanken, B. and Orbell, S. (2003), "Reflections on past behavior: A self-report index of habit strength”, Journal of Applied Social Psychology, Vol. 33 No. 6, pp. 1313-1330. 
Watkinson, A., Nicholas, D., Thornley, C., Herman, E., Jamali, H. R., Volentine, R., ... Tenopir, C. (2016), "Changes in the digital scholarly environment and issues of trust: An exploratory, qualitative analysis", Information Processing and Management, Vol. 52 No. 3, pp. 446-458.

Wood, W. and Neal, D.T. (2007), “A new look at habits and the habit-goal interface”, Psychology Review, Vol. 114 No. 4, pp. 843-863.

Wood, W. and Rünger, D. (2016), "Psychology of habit", Annual Review of Psychology, Vol. 67, pp. 289-314.

Xia, J. (2010), “A longitudinal study of scholars' attitudes and behaviors toward open-access journal publishing”, Journal of the American Society for Information Science and Technology, Vol. 61 No. 3, pp. 615-624.

Yerkes, R.M. and Dodson, J.D. (1908), “The relation of strength of stimulus to rapidity of habitformation. Journal of Comparative Neurology, Vol. 18 No. 5, pp. 459-482.

Zuiderwijk, A. and Spiers, H. (2019), "Sharing and re-using open data: A case study of motivations in astrophysics”, International Journal of Information Management, Vol. 49, pp. 228-241. 
Table 1. Standardized confirmatory factor analysis coefficients and construct reliabilities

\begin{tabular}{|c|c|c|c|c|}
\hline Constructs and indicators & $\begin{array}{l}\text { Factor } \\
\text { loadings }\end{array}$ & $\begin{array}{l}\text { t- } \\
\text { values }\end{array}$ & CA & VE \\
\hline 9. Attitudes $\mathrm{OA}$ : For me, submitting articles to $O A$ journals is... & & & 0.93 & 0.75 \\
\hline Useless - useful & 0.89 & 44.4 & & \\
\hline Bad - good & 0.87 & 43.1 & & \\
\hline Foolish - wise & 0.86 & 42.3 & & \\
\hline Unimportant - important & 0.85 & 41.7 & & \\
\hline Norms OA & & & 0.89 & 0.80 \\
\hline Most researchers I know submit their research articles to OA journals regularly. & 0.87 & 41.2 & & \\
\hline $\begin{array}{l}\text { Of the researchers you know, how many submit their research articles to OA } \\
\text { journals regularly? }\end{array}$ & 0.91 & 43.9 & & \\
\hline 11. Perceived behavioural control $\mathrm{OA}$ & & & 0.76 & 0.52 \\
\hline $\begin{array}{l}\text { How much personal control do you feel you have over submitting your research } \\
\text { articles to OA journals? }\end{array}$ & 0.60 & 23.4 & & \\
\hline $\begin{array}{l}\text { How confident are you that you will be able to submit your research articles to } \\
\text { OA journals? }\end{array}$ & 0.90 & 35.4 & & \\
\hline If I wanted to, I could easily submit my research articles to open access journals. & 0.63 & 25.0 & & \\
\hline $\begin{array}{l}\text { 12. Habit strength } \mathrm{OA} \text { : The decision to submit an article to an } \mathrm{OA} \text { journal is } \\
\text { something... }\end{array}$ & & & 0.89 & 0.61 \\
\hline ...I do automatically. & 0.89 & 43.9 & & \\
\hline ...I do without thinking. & 0.86 & 41.8 & & \\
\hline ...I would find hard not to do. & 0.73 & 32.6 & & \\
\hline ...that would require effort not to do it. & 0.70 & 30.7 & & \\
\hline ...I start doing before I realize I am doing it. & 0.72 & 32.3 & & \\
\hline Intention to submit to an $\mathrm{OA}$ journal & & & 0.98 & 0.94 \\
\hline I will try to submit research articles to OA journals within the next 2 years. & 0.96 & 51.1 & & \\
\hline I intend to submit research articles to OA journals within the next 2 years. & 0.99 & 54.7 & & \\
\hline I plan to submit research articles to OA journals within the next 2 years. & 0.95 & 51.6 & & \\
\hline 14. Intention to submit to a non-OA journal & & & 0.97 & 0.91 \\
\hline I will try to submit research articles to non-OA journals within the next 2 years. & 0.94 & 49.7 & & \\
\hline I intend to submit research articles to non-OA journals within the next 2 years. & 0.98 & 54.1 & & \\
\hline $\begin{array}{l}\text { I plan to submit research articles to non-OA journals within the next } 2 \text { years. } \\
\text { 15.Publishing behaviour } \boldsymbol{O A}\end{array}$ & 0.95 & 50.4 & & \\
\hline $\begin{array}{l}\text { How many articles would you say that you have published in OA journals within } \\
\text { the last } 2 \text { years? }\end{array}$ & 1.00 & 56.3 & - & - \\
\hline 16. Publishing behaviour non- $O A$ & & & & \\
\hline $\begin{array}{l}\text { How many articles would you say that you have published in non-OA journals in } \\
\text { the last } 2 \text { years? }\end{array}$ & 1.00 & 56.3 & - & - \\
\hline
\end{tabular}

Notes. CA: Composite reliability; VE: Variance extracted. 
Table 2. Correlations and descriptive statistics for constructs in the measurement model

\begin{tabular}{|c|c|c|c|c|c|c|c|c|c|c|}
\hline $\mathrm{N}=1,588$ & Mean & SD & 1 & 2 & 3 & 4 & 5 & 6 & 7 & 8 \\
\hline \multicolumn{11}{|c|}{ The common method CFA model } \\
\hline 9. Attitude & 5.21 & 1.55 & & & & & & & & \\
\hline 10. Norms OA & 3.18 & 1.52 & 0.55 & & & & & & & \\
\hline 11. $\mathrm{PBC} O A$ & 4.98 & 1.43 & 0.28 & 0.41 & & & & & & \\
\hline 12. Habit strength OA & 2.74 & 1.44 & 0.48 & 0.58 & 0.26 & & & & & \\
\hline 13. Intention to submit $\mathrm{OA}$ & 4.87 & 1.96 & 0.67 & 0.63 & 0.42 & 0.49 & & & & \\
\hline $\begin{array}{l}\text { 14. Intention to submit } \\
\text { non-OA }\end{array}$ & 5.07 & 1.96 & -0.35 & -0.43 & -0.15 & -0.50 & -0.28 & & & \\
\hline 15. Behaviour OA & 3.10 & 2.69 & 0.20 & 0.36 & 0.23 & 0.19 & 0.33 & -0.06 & - & \\
\hline 16. Behaviour non-OA & 4.28 & 3.19 & -0.28 & -0.24 & $-0.01^{n s}$ & -0.33 & -0.13 & 0.42 & 0.32 & - \\
\hline \multicolumn{11}{|c|}{ The basic measurement model } \\
\hline 1. Attitude & 5.21 & 1.55 & 0.87 & & & & & & & \\
\hline 2. Norms OA & 3.18 & 1.52 & 0.55 & 0.89 & & & & & & \\
\hline 3. $\mathrm{PBC} O \mathrm{OA}$ & 4.98 & 1.43 & 0.28 & 0.41 & 0.72 & & & & & \\
\hline 4. Habit strength $\mathrm{OA}$ & 2.74 & 1.44 & 0.48 & 0.56 & 0.28 & 0.78 & & & & \\
\hline 5. Intention to submit $\mathrm{OA}$ & 4.87 & 1.96 & 0.67 & 0.63 & 0.42 & 0.48 & 0.97 & & & \\
\hline $\begin{array}{l}\text { 6. Intention to submit non- } \\
\text { OA }\end{array}$ & 5.07 & 1.96 & -0.35 & -0.42 & -0.16 & -0.50 & -0.28 & 0.96 & & \\
\hline 7. Behaviour OA & 3.10 & 2.69 & 0.20 & 0.36 & 0.22 & 0.18 & 0.33 & -0.07 & - & \\
\hline 8. Behaviour non-OA & 4.28 & 3.19 & -0.28 & -0.24 & $-0.03^{n s}$ & -0.34 & -0.13 & 0.42 & 0.32 & - \\
\hline
\end{tabular}

Notes. $n s=$ not significant; Remaining correlations are significant at $\mathrm{p}<0.001$; Intention to submit $\mathrm{OA} /$ non-OA $=$ Intention to submit open access/No open access; Bold numbers in the diagonal indicate the square root of the AVE. 
Table 3. Model testing

\begin{tabular}{|c|c|c|c|c|c|c|c|c|c|c|c|}
\hline \multirow{3}{*}{ Paths } & \multirow{2}{*}{\multicolumn{2}{|c|}{$\begin{array}{c}\text { TPB } \\
\text { Model 1 } \\
\text { Basic Model }\end{array}$}} & \multicolumn{6}{|c|}{ TPB and Habit strength } & \multirow{2}{*}{\multicolumn{3}{|c|}{$\begin{array}{c}\text { Decomposed } \\
\text { Behavioural Model } \\
\text { Model } 5 \\
(\text { DBM })\end{array}$}} \\
\hline & & & \multicolumn{2}{|c|}{$\begin{array}{c}\text { Model 2 } \\
\text { (ETBP) }\end{array}$} & \multicolumn{2}{|c|}{$\begin{array}{l}\text { Model 3 } \\
\text { (HMMf) }\end{array}$} & \multicolumn{2}{|c|}{$\begin{array}{c}\text { Model } 4 \\
\text { (HMMp) }\end{array}$} & & & \\
\hline & Std. $\beta$ & $P$-value & Std. $\beta$ & $\begin{array}{c}P- \\
\text { value }\end{array}$ & Std. $\beta$ & $\begin{array}{c}P- \\
\text { value }\end{array}$ & Std. $\beta$ & $\begin{array}{c}P- \\
\text { value }\end{array}$ & $\begin{array}{c}\text { Path } \\
\text { s }\end{array}$ & Std. $\beta$ & $P$-value \\
\hline & & & & & & & & & $\mathrm{H}-\mathrm{I}_{\mathrm{a}}$ & 0.48 & *** \\
\hline $\mathrm{A}-\mathrm{I}_{\mathrm{a}}$ & 0.46 & ** & 0.44 & ** & - & - & 0.44 & ** & $\mathrm{H}-\mathrm{I}_{\mathrm{b}}$ & -0.50 & ** \\
\hline $\mathrm{N}-\mathrm{I}_{\mathrm{a}}$ & 0.30 & ** & 0.28 & ** & - & - & 0.28 & ** & $\mathrm{H}-\mathrm{B}_{\mathrm{a}}$ & 0.04 & 0.286 \\
\hline PBC- $I_{a}$ & 0.16 & ** & 0.16 & ** & - & - & 0.16 & ** & $\mathrm{H}-\mathrm{B}_{\mathrm{b}}$ & -0.19 & ** \\
\hline A-H & - & & - & - & 0.32 & $* *$ & 0.26 & $* *$ & $\mathrm{I}_{\mathrm{a}}-\mathrm{B}_{\mathrm{a}}$ & 0.34 & ** \\
\hline $\mathrm{N}-\mathrm{H}$ & - & & - & - & 0.43 & ** & 0.39 & ** & $\mathrm{I}_{\mathrm{a}}-\mathrm{B}_{\mathrm{b}}$ & 0.04 & 0.118 \\
\hline PBC-H & - & & - & - & 0.06 & 0.015 & 0.05 & 0.031 & $\mathrm{I}_{\mathrm{b}}-\mathrm{B}_{\mathrm{a}}$ & 0.06 & 0.033 \\
\hline $\mathrm{H}-\mathrm{I}_{\mathrm{a}}$ & - & & 0.05 & 0.031 & 0.59 & $* *$ & 0.05 & 0.070 & $\mathrm{I}_{\mathrm{b}}-\mathrm{B}_{\mathrm{b}}$ & 0.34 & *** \\
\hline \multicolumn{12}{|l|}{ Model fit: } \\
\hline CMIN/df & \multicolumn{2}{|c|}{4.14} & \multicolumn{2}{|c|}{4.00} & \multicolumn{2}{|c|}{10.44} & \multicolumn{2}{|c|}{4.00} & \multicolumn{3}{|c|}{3.60} \\
\hline$G F I$ & \multicolumn{2}{|c|}{0.98} & \multicolumn{2}{|c|}{0.97} & \multicolumn{2}{|c|}{0.92} & \multicolumn{2}{|c|}{0.97} & \multicolumn{3}{|c|}{0.98} \\
\hline$C F I$ & \multicolumn{2}{|c|}{0.99} & \multicolumn{2}{|c|}{0.99} & \multicolumn{2}{|c|}{0.95} & \multicolumn{2}{|c|}{0.99} & \multicolumn{3}{|c|}{0.99} \\
\hline RMSEA & \multicolumn{2}{|c|}{0.044} & \multicolumn{2}{|c|}{0.044} & \multicolumn{2}{|c|}{0.077} & \multicolumn{2}{|c|}{0.044} & \multicolumn{3}{|c|}{0.040} \\
\hline $\mathrm{R}^{2} \mathrm{I}_{\mathrm{a}}$ & \multicolumn{2}{|c|}{0.564} & \multicolumn{2}{|c|}{0.566} & \multicolumn{2}{|c|}{0.347} & \multicolumn{2}{|c|}{0.566} & \multicolumn{3}{|c|}{0.232} \\
\hline$R^{2} I_{b}$ & & - & & & & & & & & 0.253 & \\
\hline $\mathrm{R}^{2} \mathrm{~B}_{\mathrm{a}}$ & & - & & & & & & & & 0.123 & \\
\hline $\mathrm{R}^{2} \mathrm{~B}_{\mathrm{b}}$ & & - & & & & & & & & 0.205 & \\
\hline $\mathrm{R}^{2} \mathrm{H}$ & & - & & 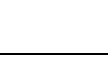 & & 87 & & & & - & \\
\hline
\end{tabular}

Notes. $\mathrm{N}=1,588 ;{ }^{* *}=p<.001 ;$ Attitudes (A); Norms (N); Perceived behavioural control (PBC);

Habit $(\mathrm{H})$; Intention to submit OA $\left(\mathrm{I}_{\mathrm{a}}\right)$; Intention to submit non-OA $\left(\mathrm{I}_{\mathrm{b}}\right)$; Behaviour OA $\left(\mathrm{B}_{\mathrm{a}}\right)$;

Behaviour non-OA $\left(\mathrm{B}_{\mathrm{b}}\right)$. 